\title{
Classification of Robust and Rotten Apples by Deep Learning Algorithm
}

\author{
Kiyas KAYAALP ${ }^{1}$, (D) Sedat METLEK ${ }^{2}$ \\ ${ }^{1}$ Corresponding Author; Isparta Uygulamalı Bilimler Üniversitesi, Uluborlu Selahattin Karasoy Meslek \\ Yüksekokulu, Bilgisayar Teknolojileri Bölümü, Isparta, Türkiye; \\ kiyaskayaalp@isparta.edu.tr; https://orcid.org/0000-0002-6483-1124; +902465312622 \\ ${ }^{2}$ Burdur Mehmet Akif Ersoy Üniversitesi, Teknik Bilimler Meslek Yüksekokulu, Elektronik ve Otomasyon \\ Bölümü, Burdur, Türkiye; sedatmetlek@mehmetakif.edu.tr; https://orcid.org/0000-0002-0393-9908
}

Received 09 April 2020; Revised 18 May 2020 Accepted 29 May 2020; Published online 28 August 2020

\begin{abstract}
In the study, it is aimed to classify the apples as rotten and robust by using the deep learning algorithm of the apple images taken from the CAPA database. In the proposed model, the processing steps are image reading, preprocessing and classification of apples, respectively. In the image reading stage, images taken from the image database were used. The applied deep learning architecture consists of introduction, convolutional, activation, pooling, memorization, full connection and conclusion layers. The data used in this architecture are divided into two as $80 \%$ training and $20 \%$ test data. Four different wavelength, 16 kinds of image combinations were used for the training and testing of the system. At the classification stage, a success rate of $91.25 \%$ was achieved in detecting rotten and robust apples. As a result, it is predicted that the proposed model can be used in the fruit processing industry to automatically classify rotten and robust apples.
\end{abstract}

Keywords: apple classification, deep learning, image processing, rotten, apple

\section{Sağlam ve Çürük Elmaların Derin Öğrenme Algoritması ile Sinıflandırılması}

\section{Öz}

Yapılan çalışmada, CAPA veri tabanından alınan elma görüntülerinin derin öğrenme algoritması kullanılarak, elmaların çürük ve sağlam olarak sınıflandırılması amaçlanmıştır. Önerilen modelde işlem adımları sırasıyla görüntü okuma, önişleme ve elmaların sınıflandırılmasıdır. Görüntü okuma aşamasında, görüntü veri tabanından alınan görüntüler kullanılmıştır. Uygulanan derin öğrenme mimarisi giriş, evrişimsel, aktivasyon, havuzlama, ezberleme, tam bağlantı ve sonuçlandırma katmanlarından oluşmaktadır. Bu mimaride kullanılan veriler, \%80 eğitim ve \%20 test verisi olmak üzere ikiye ayrılmıştır. Sistemin eğitim ve test işlemleri için dört farklı dalga boyunda, 16 çeşit görüntü kombinasyonu kullanılmıştır. Sınıflandırma aşamasında, çürük ve sağlam elmaların tespit edilmesinde \%91.25 başarı oranına ulaşılmıştır. Sonuç olarak, önerilen modelin meyve işleme sanayisinde çürük ve sağlam elmaların otomatik olarak sınıflandırılmasında kullanılabileceği ön görülmektedir.

Anahtar Kelimeler: elma sınıflandırma, derin öğrenme, görüntü işleme, çürük, elma

\section{Giriş}

Elmanın, içerdiği mineral ve vitaminler açısından beslenmedeki rolü büyüktür. Taze bir elmanın \%84'ünü su oluşturmaktadır. Geri kalan \%16'lık kuru kısmında ise karbonhidratlar, proteinler, vitaminler, pektinler ve çeşitli mineraller bulunmaktadır. Bu minerallerin kandaki asit-baz dengesi üzerinde olumlu etkileri bulunmaktadır. Özellikle günde bir elma yemenin kanser riskini dahi önemli ölçüde azalttı̆̆ tespit edilmiştir [1].

Elma, dünya üzerindeki toplam meyve üretiminin yaklaşık \%12'sini oluşturarak, muzdan sonra ikinci sırada yer alan önemli bir meyve türüdür. Bununla beraber elma gıda sektöründe, reçel, elma suyu, elma 
şırası ve sirke gibi ürünlerin ham maddesi olarak kullanılmaktadır. Ayrıca, üretimin son aşamasında atık olarak elde edilen elma posasında bile insan sağlığı için önemli olan pektin maddesi bulunmaktadır [2].

Elma posasının bile bu kadar önemli olmasının yanı sıra meyve olarak tüketilmesi de oldukça önemlidir. $\mathrm{Bu}$ nedenle elmaların meyve olarak tüketilmesi için ilk olarak sağlam ve çürük elmaların ayırt edilmesi gerekmektedir. $\mathrm{Bu}$ ayrım işlemi, teknolojinin gelişmesine bağlı olarak sınıflandırma makineleri tarafından yapılmaktadır. Bu makineler görüntü işleme tabanlı çalışmakla beraber, kontrol mekanizmalarının içerisinde birçok sınıflandırma algoritması bulundurmaktadır.

Teknolojinin gelişmesine paralel olarak sınıflandırma algoritmalarında da sürekli yeni yöntemler geliştirilmektedir. Bu sınıflandırma algoritmaları da görüntüden elde edilen öznitelikleri temel alarak sınıflandırma yapmaktadır. Bu nedenle elma görüntülerinde bulunan sap ve taç kısımları ile çürükler karıştırılmakta ve bu kısımlar bazen çürük olarak nitelendirilebilmektedir. Bu durum ile ilgili olarak literatürde yapılan sinıflandırmalarda iki yaklaşım mevcuttur. Bunlardan ilkinde elma görüntülerinde sap ve taç bölgeleri bulunmamaktadır. Böylece geri kalan elma yüzey görüntüleri üzerinde sağlam ve çürük sınıflandırılması yapılmaktadır. Diğer yaklaşımda ise elma görüntülerinde sap ve taç bölgeleri bulunmaktadır. Bu yaklaşımda görüntülerden ilk olarak sap ve taç bölgeleri ayırt edilmekte ve akabinde sınıflandırma işlemi gerçekleştirilmektedir [3].

Leemans ve arkadaşları 2002 yılında yaptıkları çalışmada, 1170 adet elma görüntüsünden (528 Golden Delicious, 642 Jonagold) oluşan görüntü veri tabanını kullanarak, sağlam ve çürük meyve sınıflandırmasını gerçekleştirmişlerdir. Elma sınıflandırma işlemini; görüntü elde etme, zemin renk sınıflandırması, kusur bölümlendirme, sap-taç tanıma, kalite sınıflandırma ve meyve sınıflandırma olarak altı adımda gerçekleştirmişlerdir. Golden Delicious'da \%78 ve Jonagold'da \%72 oranında sınıflandırma başarısı elde etmişlerdir [4].

Sofu ve arkadaşlarının 2013 yılında, tasarladıkları sistem ile elma görüntülerini elde etmişlerdir. Geliştirdikleri yazılım ile elmaların renk tahmininde \%99 ve cins tahmininde \%95.52 doğrulukla sınıflandırma başarısını yakalamışlardır. Uygulanan algoritma sayesinde, elma üzerindeki lekelerin tespitini herhangi bir filtreye gereksinim duymadan $\% 70$ başarı ile gerçekleştirmişlerdir [5].

2016 yılında, Cömert ve arkadaşları 600 adet sağlam, 600 adet çürük elma görüntüsünden oluşan bir veri tabanı kullanarak, elmaları sınıflandırmışlardır. Görüntü alma-önişleme, çürük bölgelerin tespit edilmesi ve elmaların sınıflandırması olmak üzere 3 adımda oluşturdukları modelde, evrişimsel sinir ağı yöntemlerinden olan Faster R-CNN yöntemini kullanmışlardır. Derin öğrenme ve görüntü işlemenin birlikte kullanıldığı bu yaklaşım sayesinde \%84.95 doğru sınıflandırma oranına ulaşmışlardır [3].

Lu ve arkadaşı 2018 yılındaki çalışmalarında, elmaların yüzey ve yüzey altı kusurlarının daha iyi algılanması için aydınlatmanın önemi üzerinde durmuşlardır. Bu nedenle aydınlatmanın direkt bileşeni, genlik bileşeni ve bunların kombinasyonlarını kullanarak elde ettikleri görüntüler ve esnek hesaplama yöntemleri sayesinde sınıflandırma işlemlerini gerçekleştirmişlerdir [6].

Siddiqi 2019 yılında yaptığı çalışmasında, 244 çürük elma görüntüsünden oluşan bir görüntü veri tabanını kullanarak elmaları sınıflandırmıştır. Bu sınıflandırmada, çürük elmalardaki çürügün yerini bulmak için YOLO (you only look once) ve SSD (single shot multibox detector) yöntemlerini kullanmıştır. SSD tabanlı sistemin YOLO tabanlı sisteme göre daha başarılı olduğunu tespit etmiştir [7].

Yu ve arkadaşları 2019 yılında, elma görüntüleri üzerindeki sap ve taç bölgeleri ile çürük bölgelerin ayrımını yapmak için bir çalışma gerçekleştirmişlerdir. Bu çalışmada elmaların alt, üst ve diğer yüzey görüntülerinin bulunduğu gri formatta bir görüntü veri tabanı üzerinde çalışmışlardır. Bu veri tabanındaki 60 adet elma görüntüsünü eğitim, 30 adet elma görüntüsünü de test için kullanmışlardır. Hazırladıkları algoritmada K-means kümeleme yöntemi sayesinde $\% 96$ sınıflandırma başarı oranını elde etmişlerdir [8].

Görüntü işleme ile elma sınıflandırılması işlemlerinde kullanılan teknolojilerin gün geçtikçe geliştiği görülmektedir. Bunun ile birlikte, donanım teknolojisinin değişmesine paralel olarak gelişen birçok güncel sınıflandırma algoritması bulunmaktadır. Bu çalışmada güncel sınıflandırma algoritmalarından olan derin öğrenme algoritması kullanılmıştır. Gerçekleştirilen çalışmada, CAPA veri tabanından alınan 
Kayaalp et. al

görüntülerin derin öğrenme algoritması kullanılarak, elmaların çürük ve sağlam olarak sınıflandırılması sağlanmıştır.

\section{Materyal ve Metot}

Çalışmada, Gembloux Tarım Üniversitesinde bir araştırma sonucunda, Jonagold elma görüntülerinin oluşturduğu CAPA görüntü veri tabanı kullanılmıştır. Bu veri tabanındaki görüntüler 450, 500, 750 ve $800 \mathrm{~nm}$ dalga boyunda alınmıştır. Alınan görüntüler sağlam, çürük, sap ve taç kısımlarının görüntüleri olmak üzere dörde ayrılmaktadır. Bu görüntülerden 280 adeti sağlam, 246 adeti çürük, 148 adeti sap ve 145 adeti taç görüntüleridir. Belirtilen her bir görüntünün de dört farklı dalga boyutunda kombinasyonu bulunmaktadır. Bu nedenle görüntü veri tabanı toplamda 3276 adet görüntüden oluşmaktadır. Çalışmada kullanılan çürük görüntüleri çeşitli dış yüzey kusurlarına (pas rengi, morarma, çürüme, güneş yanığı, dolu hasarı gibi) sahiptir. Bu görüntüler $430 \times 560$ piksel boyutlarında ve her bir piksel başına 8 bit çözünürlüğe sahiptir [9]. Gerçekleştirilen çalışmada sadece 280 adet sağlam, 246 adet çürük olmak üzere toplam 526 adet elma görüntüsü kullanılmıştır. Kullanılan görüntüler içerisinde sap ve taç kısımları bulunmamaktadır.

Literatürde son yıllarda yapılan, elma görüntülerinden sağlam ve çürük olarak sınıflandırma ile ilgili yapılan çalışmalar incelendiğinde, hiperspektral ve multispektral görüntüleme sistemlerinin kullanıldığı görülmektedir [10-16]. Fakat tercih edilen sistemlerin genellikle laboratuvar ortamında çalışabilecek nitelikte olduğu ve maliyetlerinin ise çok fazla olduğu görülmektedir. Bu sebeple, ilerleyen dönemlerde maliyeti daha düşük sistemlerle bu görüntülerin alınacağı aşikardır. Ancak, geliştirilen yazılımların bu sistemler ile entegrasyonunun sağlanması daha da önem kazanmaktadır. Günümüzde birçok sisteme entegre edilebilen derin öğrenme algoritmalarının tarım sektöründe de birçok alt alana uygulanmaktadır. $\mathrm{Bu}$ nedenle çalışmamızda güncel sınıflandırma algoritmalarından olan derin öğrenme ile çürük ve sağlam elmaların sınıflandırma işlemleri test edilmiş ve uygulanmıştır.

\subsection{Derin Öğrenme}

Günümüzün popüler konularından olan derin öğrenme, esnek hesaplama yöntemlerinin en son geldiği noktalardan birisidir. İlk esnek hesaplama modellerinden olan yapay sinir ağları (YSA), zamanla geliştirilerek Evrişimsel Sinir Ağı (ESA) modelleri oluşturulmuştur. Derin öğrenme mimarisinin temelini de geliştirilen ESA'lar oluşturmaktadır. İlk YSA modellerinde geliştiriciler sırasıyla, öznitelik elde etme ve en iyi öznitelikleri seçme işlemlerini gerçekleştirdiler [17]. Sonrasında geliştirilen ESA modellerinde ise, geliştiriciler ellerindeki verilerden öznitelik çıkarma işlemini, ESA'nın içerisinde bulunan filtrelere yaptırmışlardır. Ayrıca, bu filtreler sayesinde elde edilen veriler ESA'da doğrudan kullanılmaktadır. ESA sonucunda elde edilen veriler istenildiğinde farklı sınıflandırma algoritmalarında da kullanabilmektedir. Derin öğrenme algoritmalarında ise, tüm öznitelik çıkarma işlemleri geliştirilen ESA'larda olduğu gibi filtreler yardımı ile otomatik olarak yapılmaktadır [18].

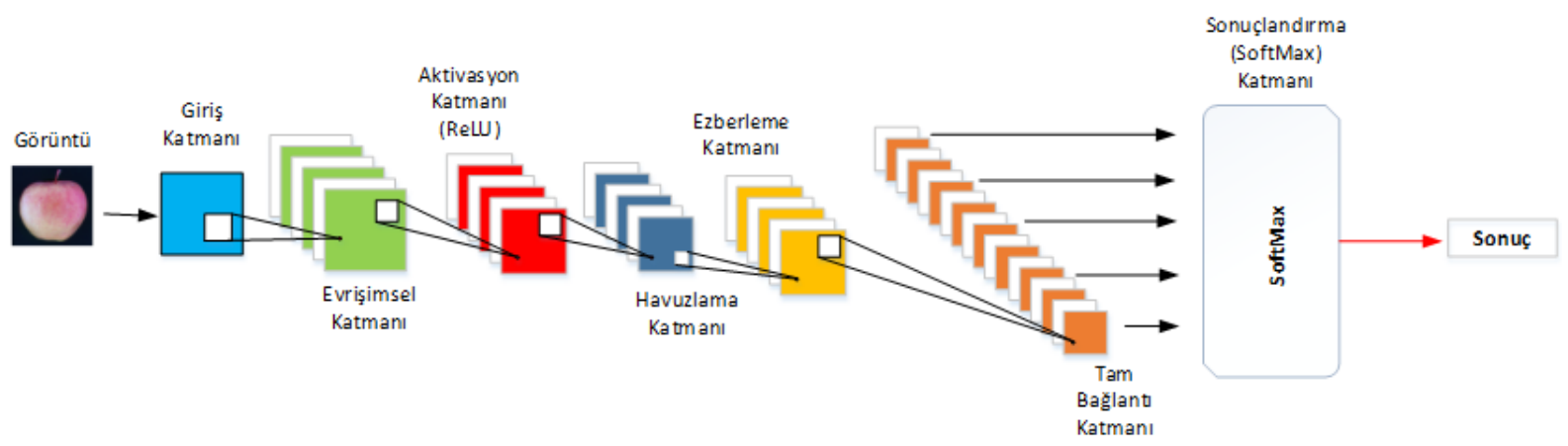

Şekil 1 Derin öğrenme mimarisi

Bunun ile birlikte sınıflandırma algoritması da bu ağ yapısının içerisinde bulunan softmax katmanında gerçekleştirilmektedir [19]. Derin Öğrenme algoritmalarında, geliştiricilerin sadece dışarıdan uygun veri tiplerini ağa sunması yeterlidir. Kullanımının bu denli kolay olmasından dolayı pek çok farklı 
Kayaalp et. al

araştırma alanında olduğu gibi uygulama ağırlıklı olan tarım teknolojilerinde de derin öğrenme algoritmaları yaygın olarak kullanılmaya başlanmıştır [20].

Derin Öğrenme mimarilerinin özellikle görüntü işleme ve sınıflandırma uygulamalarında yaygın olarak kullanıldığı görülmektedir [21-23]. Bu çalışmada da görüntüler üzerinden sınıflandırılma yapılacak olması nedeniyle derin öğrenme algoritması tercih edilmiştir. Kullanılan derin öğrenme mimarisinin genel yapısı Şekil 1'de verilmiştir.

Şekil 1'de gösterildiği üzere derin öğrenme mimarisi kendi içerisinde katmanlı bir yapıya sahiptir. Bu katmanlar sırasıyla; giriş, evrişimsel, aktivasyon, havuzlama, ezberleme, tam bağlantı ve sonuçlandırma katmanlarıdır. Bu katmanların detayları Tablo 1'de gösterilmiştir.

Tablo 1 Derin öğrenme modeli katmanları ve özellikleri

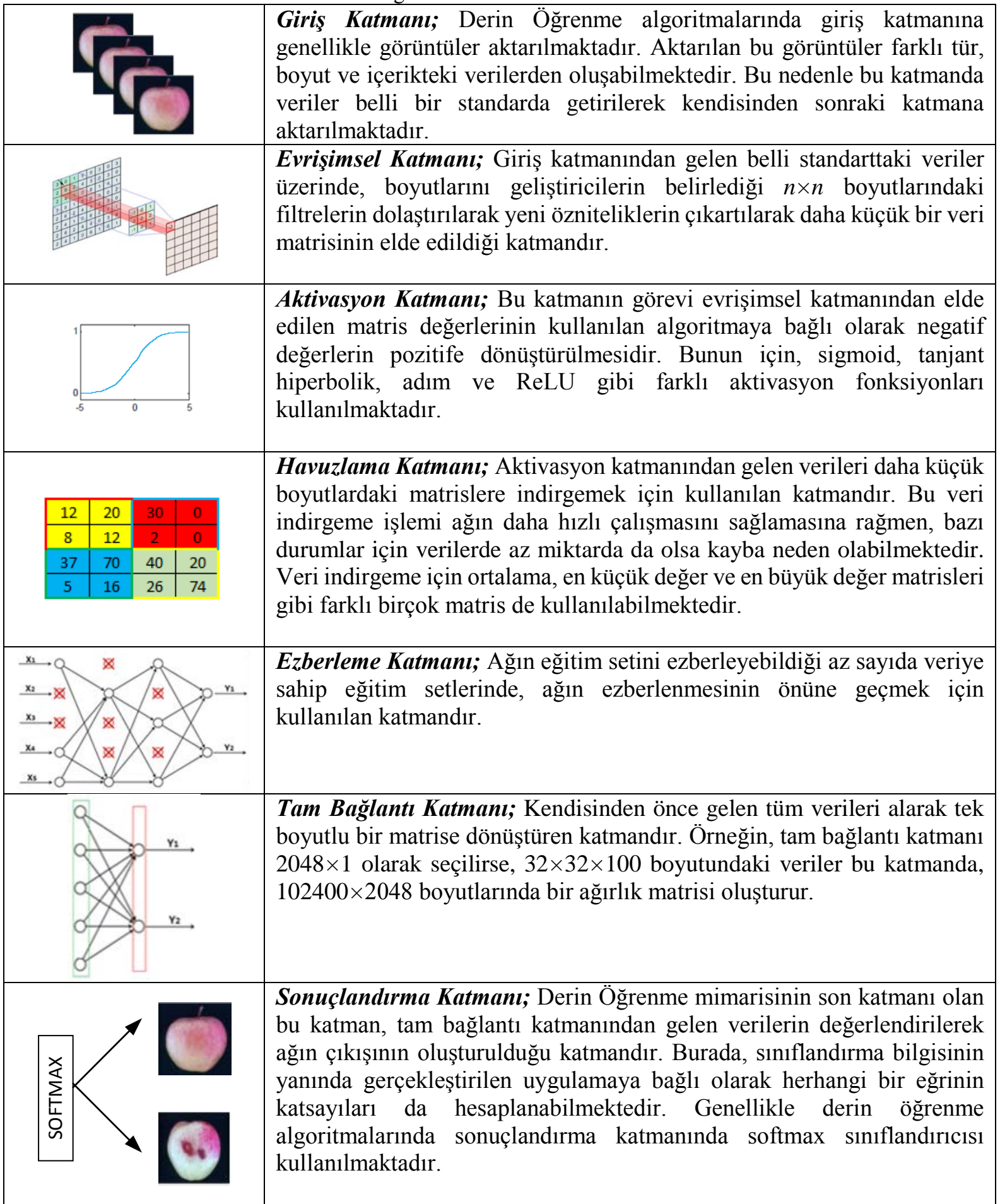


Kayaalp et. al

\section{Bulgular ve Tartışma}

Gerçekleştirilen uygulama Matlab ortamında, CAPA görüntü veri tabanı üzerinde Şekil 2'de gösterilen derin öğrenme mimarisi kullanılarak sağlam ve çürük elmaların sınıflandırılması sağlanmıştır. $\mathrm{Bu}$ aşamada ilk olarak sistemdeki 4 farklı dalga boyunda kaydedilen görüntüler alınarak sistemin girişini oluşturacak bir veri tabanı oluşturulmuştur.

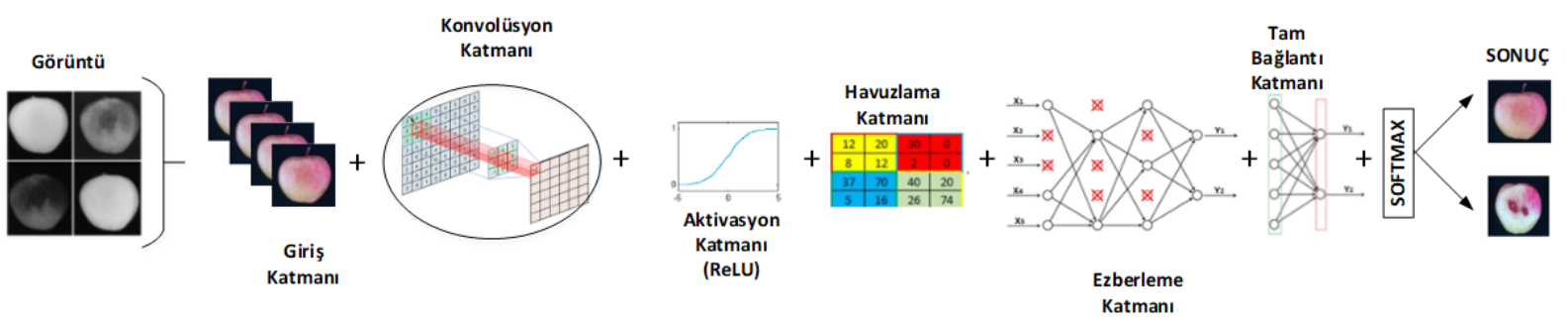

Şekil 2 Elma sınıflandırmasında kullanılan genel derin öğrenme mimarisi

Elmaların farklı dalga boylarındaki görüntülerine ek olarak, RGB formatındaki sonuçların daha iyi çıkabilme ihtimali için görüntülerin RGB formatı elde edilerek, hazırlanan yeni veri tabanına eklenmiştir. Şekil 3'de veri tabanında bulunan, iki farklı sınıftaki elmaya ait görüntüler, sırasıyla gösterilmiştir.
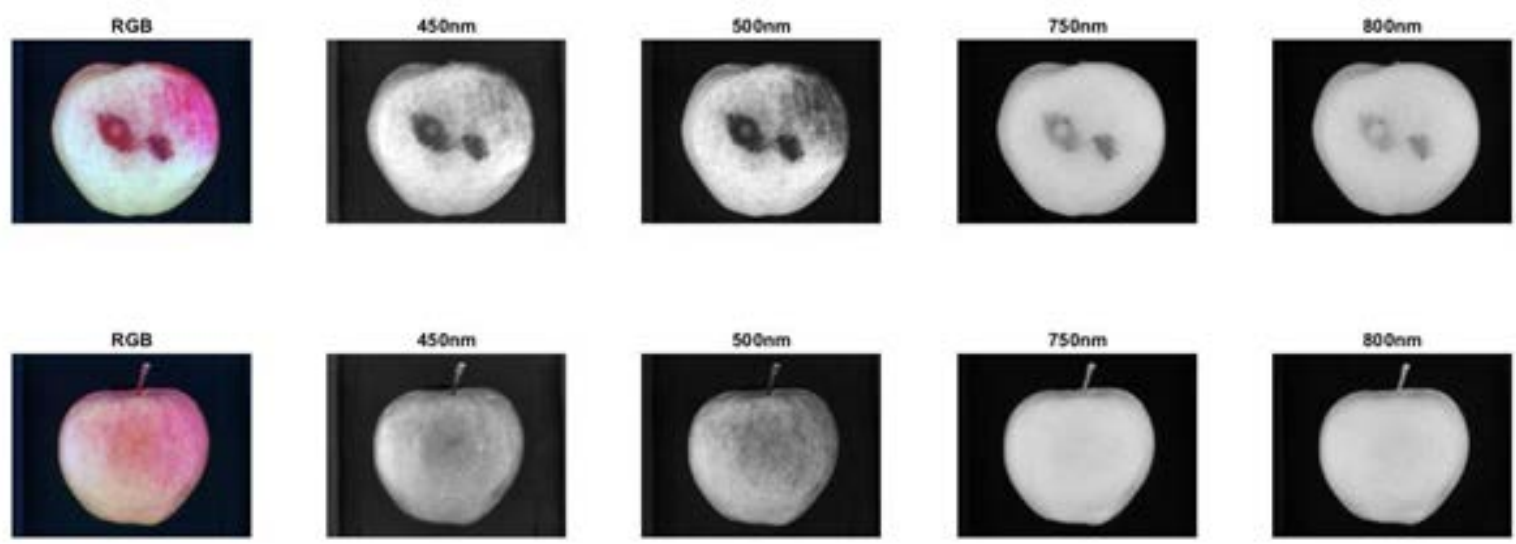

Şekil 3 Çürük ve sağlam elmaya ait RGB ve tüm dalga boylarındaki görüntüleri

Veri tabanı oluşturma işleminden sonra, alınan görüntüler katmanlı mimariye sahip derin öğrenme algoritmasına gönderilmiştir. Çalışmada kullanılan mimari arka arkaya üç adet evrişimsel yapının eklenmesi ile oluşturulmuştur. Oluşturulan her bir evrişimsel yapıda (Şekil 4) sirasıyla; evrişimsel $(3 \times 8)$, normalizasyon, aktivasyon (sigmoid), havuzlama $(2 \times 2$ enbüyük), evrişimsel $(3 \times 16)$, normalizasyon, aktivasyon (sigmoid), havuzlama $(2 \times 2$ enbüyük), evrişimsel $(3 \times 32)$, normalizasyon, aktivasyon (sigmoid), havuzlama $(2 \times 2$ enbüyük) katmanları bulunmaktadır. Mimarinin son katmanında ise, tam bağlantı ve softmax katmanı bulunmaktadır.

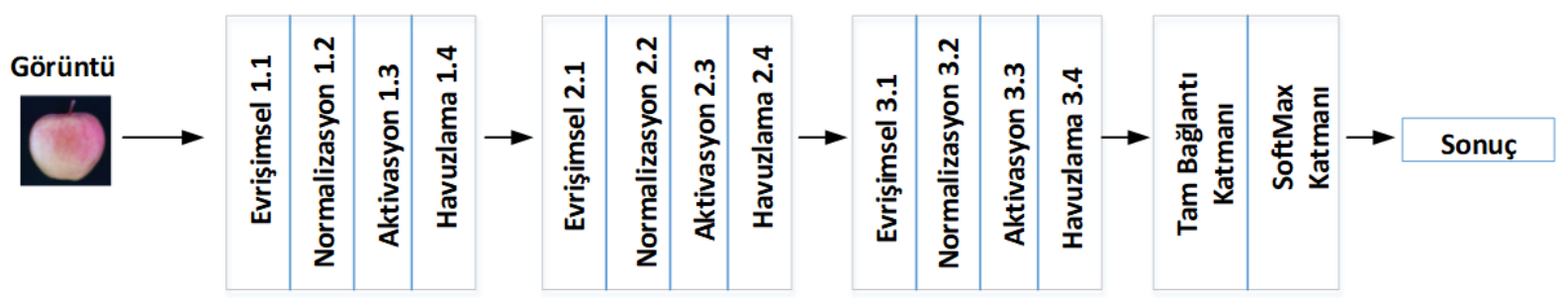

Şekil 4 Çalışmada kullanılan derin öğrenme sınıflandırma mimarisi

Tasarlanan yapının eğitilmesinde k-fold 4 değeri için verilerin \%80'i eğitim, \%20'si test verisi olarak kullanılmıştır. Bunun yanında, öğrenme katsayısı olarak 0.005 değeri alınmıştır. Sistemin eğitim ve test işlemleri için RGB renk uzayındaki değeri ve Tablo 3'de kullanılan farklı dalga boylarındaki değerleri sırasıyla test edilmiştir. 
Kayaalp et. al

Hata (Confusion) matrisi bir sınıflandırma modelinin tahminlerinin, ne kadar başarılı olduğunu özetleyen $\mathrm{M} \times \mathrm{M}$ şeklide bir tablodur. Bu tablonun bir ekseninde tahmin edilen sonuçlar, diğer ekseninde de gerçek değerler gösterilir. Hata matrisi, sınıflandırıcı tarafından yapılan hataları ve hata türleri hakkında, aynı zamanda da model performansı konusunda genel bilgi verir. Bu nedenle gerçekleştirilen çalışmanın hata matrisi Tablo 2'de sunulmuştur.

Tablo 2 Hata matrisi

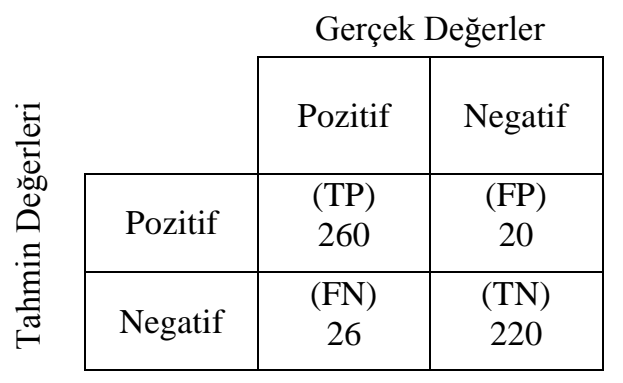

Tablo 2'de, "TP" tahmin sonucu pozitif gerçek değeride pozitif olanı, "FN" tahmin sonucu negatif gerçek değeride pozitif olanı, "TN" tahmin sonucu negatif gerçek değeride negatif olanı, "FP" tahmin sonucu pozitif gerçek değeride negatif olan değerleri ifade etmektedir.

Doğruluk (Accuracy), doğru tahmin edilen örneklerin (TP ve TN), toplam tahmin edilen örneklere bölünmesiyle elde edilir. Yapılan çalışmanın doğruluğu Denklem 1 ile hesaplanmış ve \%91.25 olarak bulunmuştur.

$$
\text { Doğruluk }=\frac{T P+T N}{T P+F P+F N+T N}
$$

Tablo 3'de test görüntüleri ile tüm sistemden elde edilen sınıflandırma başarısı ayrıntılı olarak verilmiştir. Tablo 3'de de görüldügü üzere $450 \mathrm{~nm}$ ile $500 \mathrm{~nm}$ dalga boylarında $\% 91.25$ başarı oranı ile sınıflandırma işlemi gerçekleştirilmiştir. Elde edilen başarım oranının literatürde bulunan benzer çalışmalarla ayrıntılı olarak kıyaslaması Tablo 4'de sunulmuştur. Önerilen model aynı veri tabanını kullanan diğer çalışmalar [4,26,27] ile karşılaştırıldığında, sadece üç evrişimsel katman ile \%91.25 başarı oranını yakalamış bulunmaktadır. Bu nedenle, çalışmaya daha fazla sayıda evrişimsel katman eklenerek bu oranın çok daha yukarıya çekilebileceği açıkça ön görülmektedir. Şu anki çalışmada temelde sadece üç evrişimsel katman kullanılarak, birçok gömülü sisteme de kolayca adapte edilebilecek bir yapı sunulmuştur.

Tablo 3 Sınıflandırma başarı sonuçları

\begin{tabular}{|c|l|c|c|}
\hline No & \multicolumn{1}{|c|}{ Kullanılan Değerler } & İterasyon & Başarı Oranı \% \\
\hline 1 & RGB & 1000 & 75.91 \\
\hline 2 & $450 \mathrm{~nm}, 500 \mathrm{~nm}, 750 \mathrm{~nm}$, 800nm & 1000 & 86.35 \\
\hline 3 & $450 \mathrm{~nm}, 500 \mathrm{~nm}, 750 \mathrm{~nm}$ & 1000 & 88.87 \\
\hline 4 & $450 \mathrm{~nm}, 500 \mathrm{~nm}, 800 \mathrm{~nm}$ & 1000 & 87.06 \\
\hline 5 & $450 \mathrm{~nm}, 750 \mathrm{~nm}, 800 \mathrm{~nm}$ & 1000 & 84.33 \\
\hline 6 & $500 \mathrm{~nm}, 750 \mathrm{~nm}, 800 \mathrm{~nm}$ & 1000 & 85.56 \\
\hline 7 & 450nm, 500nm & $\mathbf{1 0 0 0}$ & $\mathbf{9 1 . 2 5}$ \\
\hline 8 & $450 \mathrm{~nm}, 750 \mathrm{~nm}$ & 1000 & 88.70 \\
\hline 9 & $450 \mathrm{~nm}, 800 \mathrm{~nm}$ & 1000 & 87.09 \\
\hline 10 & $500 \mathrm{~nm}, 750 \mathrm{~nm}$ & 1000 & 86.53 \\
\hline 11 & $500 \mathrm{~nm}, 800 \mathrm{~nm}$ & 1000 & 85.16 \\
\hline 12 & $750 \mathrm{~nm}, 800 \mathrm{~nm}$ & 1000 & 75.97 \\
\hline 13 & $450 \mathrm{~nm}$ & 1000 & 89.45 \\
\hline 14 & $500 \mathrm{~nm}$ & 1000 & 90.71 \\
\hline 15 & $750 \mathrm{~nm}$ & 1000 & 71.38 \\
\hline 16 & $800 \mathrm{~nm}$ & 1000 & 72.40 \\
\hline
\end{tabular}


Kayaalp et. al

Tablo 4 Elmalarda çürük tespiti için literatürde yapılmış çalışmalar

\begin{tabular}{|c|c|c|c|c|c|}
\hline Yazar & Yıl & $\begin{array}{l}\text { Elma } \\
\text { Türü }\end{array}$ & $\begin{array}{l}\text { Görüntü } \\
\text { Sayısı }\end{array}$ & Yöntem & $\begin{array}{c}\text { Başarı } \\
\text { Oranı } \\
(\%)\end{array}$ \\
\hline Leemans ve diğ. [4] & 2002 & Jonagold & 642 & Tek gizli katmanlı YSA & 72 \\
\hline Leemans ve diğ. [4] & 2002 & $\begin{array}{l}\text { Golden } \\
\text { Delicious }\end{array}$ & 528 & Tek gizli katmanlı YSA & 78 \\
\hline $\begin{array}{l}\text { Leemans ve Destain } \\
\text { [24] }\end{array}$ & 2004 & Jonagold & 400 & Kmeans kümeleme & 73 \\
\hline $\begin{array}{l}\text { Xing ve } \\
\text { Baerdemaeker [25] }\end{array}$ & 2005 & Jonagold & 160 & $\begin{array}{l}\text { Yumuşatma, Eşikleme, } \\
\text { Hyperspectral görüntüleme }\end{array}$ & 77.5 \\
\hline $\begin{array}{l}\text { Unay ve Gosselin } \\
\text { [26] }\end{array}$ & 2006 & Jonagold & 526 & $\begin{array}{l}\text { CNN, SOM, k-NN, LDC, QDC, LR, } \\
\text { SVM, MLP, CFNN, ENN, LVQ }\end{array}$ & 84.8 \\
\hline Unay ve diğ. [27] & 2011 & Jonagold & 526 & $\begin{array}{l}\text { LDC, k-NN, Fuzzy k-NN, SVM, } \\
\text { C4.5 }\end{array}$ & 93.5 \\
\hline $\begin{array}{l}\text { Mohana ve } \\
\text { Prabhakar [28] }\end{array}$ & 2015 & Jonagold & 200 & $\begin{array}{l}\text { Multifractal, Fourier ve Radon } \\
\text { dönüşümleri, SVM, ANN, k-NN, } \\
\text { LDC ve AdaBoost }\end{array}$ & 94 \\
\hline Dubey ve Jalal [29] & 2015 & $\begin{array}{l}\text { Farklı } \\
\text { türler }\end{array}$ & 320 & $\begin{array}{l}\text { Lab-HSV Renk Uzayları, Kmeans } \\
\text { kümeleme, SVM }\end{array}$ & 93 \\
\hline Lu ve Lu [30] & 2017 & Fuji & 120 & $\begin{array}{l}\text { Hyperspectral görüntüleme, Ridler, } \\
\text { Unimode ve Otsu eşikleme }\end{array}$ & 90 \\
\hline Zhang ve diğ. [31] & 2017 & Fuji & 155 & SVM, Hyperspectral & 92.5 \\
\hline Cömert ve diğ. [3] & 2019 & $\begin{array}{l}\text { Farkl1 } \\
\text { türler }\end{array}$ & 1200 & Faster R-CNN & 84.95 \\
\hline Önerilen Metot & 2020 & Jonagold & 526 & Deep Learning (Softmax) & 91.25 \\
\hline
\end{tabular}

\section{Sonuç}

Bu çalışmada gıda sektöründe oldukça fazla alanda kullanılan bir ürün olan elmanın sağlam ve çürük olarak sınıflandırılması amaçlanmıştır. Bu amaç doğrultusunda, CAPA görüntü veri tabanı ve derin öğrenme algoritması kullanılarak, sağlam ve çürük elmalar sınıflandırılmıştır. Kullanılan görüntü veri seti tekrar düzenlenmiş ve farklı dalga boylarında 16 değişken durum göz önünde bulundurularak eğitim ve test işlemleri gerçekleştirilmiştir. $450 \mathrm{~nm}$ ve $500 \mathrm{~nm}$ dalga boylarının birlikte kullanıldığı görüntülerden elde edilen öznitelikler ile başarı oranının \%91.25 olduğu tespit edilmiştir.

Laboratuvar ortamlarında oluşturulan görüntü işleme tabanlı çalışan otomasyon sistemleri genellikle kamera, aydınlatma ve bilgisayardan oluşmaktadır. Bunların kontrolü ise çoğu zaman manuel olarak yapılmaktadır. Halbuki üretim ortamlarında çalışan otomasyon sistemleri ise kamera, endüstriyel bilgisayar, aydınlatma üniteleri, motor sürücü üniteleri gibi kompleks bir sistemden oluşmaktadır. Bunların kontrolüde otomatik olarak yapılmaktadır. Üretim ortamındaki sistemlerin hızlı bir şekilde çalışabilmesi için yazılım ve donanım uyumunun olması şarttır. Halbuki laboratuvar ortamında gerçekleştirilen sistemlerde böyle bir uyum ve hız aranmamaktadır. Günümüzde ise teknolojinin gelişmesine bağlı olarak işlem kapasitesi yüksek birçok gömülü sistem geliştirilmiştir. Buna paralel olarak da daha öncesinde ayrı yazılım ve donanım sistemleri birleştirilerek tek platformda gerçekleştirilmektedir [32]. Gerçekleştirilen algoritma gömülü sistem üzerinde çalıştırılabilecek nitelikte olduğu için kameradan görüntü alma, alınan görüntüyü işleme ve dış ortamda bulunan kontrol kartları ve sürücülerin kontrol edilmesi yazılımsal olarak aynı platfomda geliştirilebilecektir. Bu nedenle çalışmanın başarı oranı, tüm sistemin gerçek üretim ortamlarındaki durumu göz önüne alındığında kullanılabilecek niteliktedir. 


\section{Referanslar}

[1] H. Kurt, Ş. Ö. Keşkek, T. Çil, and A. Canataroğlu, "Meme kanserli hastalarda tamamlayıc1/alternatif tedavi kullanımı," Türk Onkol. Derg., vol. 28, no. 1, pp. 10-15, 2013.

[2] C. A. Perussello, Z. Zhang, A. Marzocchella, and B. K. Tiwari, "Valorization of apple pomace by extraction of valuable compounds,” Compr. Rev. Food Sci. Food Saf., vol. 16, no. 5, pp. 776796, 2017.

[3] O. Cömert, M. Hekim, and K. Adem, "Faster R-CNN Kullanarak Elmalarda Çürük Tespiti,” Uluslararası Mühendislik Araştırma ve Geliştirme Derg., vol. 11, no. 1, pp. 335-341.

[4] V. Leemans, H. Magein, and M.-F. Destain, "On-line fruit grading according to their external quality using machine vision,” Biosyst. Eng., vol. 83, no. 4, pp. 397-404, 2002.

[5] M. M. Sofu, O. Er, M. C. Kayacan, and B. Cetişli, "Elmaların görüntü işleme yöntemi ile sinıflandırılmasi ve leke tespiti," Glda Teknol. Elektron. Derg., vol. 8, no. 1, pp. 12-25, 2013.

[6] Y. Lu and R. Lu, "Detection of surface and subsurface defects of apples using structuredillumination reflectance imaging with machine learning algorithms," Trans. ASABE, vol. 61, no. 6, pp. 1831-1842, 2018.

[7] R. Siddiqi, “Automated apple defect detection using state-of-the-art object detection techniques,” SN Appl. Sci., vol. 1, no. 11, p. 1345, 2019.

[8] Y. Yu, S. A. Velastin, and F. Yin, "Automatic grading of apples based on multi-features and weighted K-means clustering algorithm,” Inf. Process. Agric., 2019.

[9] O. Kleynen, V. Leemans, and M.-F. Destain, "Development of a multi-spectral vision system for the detection of defects on apples," Journal of Food Engineering, vol. 69, no. 1, pp. 41-49, 2005.

[10] B. Zhang et al., "Principles, developments and applications of computer vision for external quality inspection of fruits and vegetables: A review,” Food Res. Int., vol. 62, pp. 326-343, 2014.

[11] S. Cubero, W. S. Lee, N. Aleixos, F. Albert, and J. Blasco, "Automated systems based on machine vision for inspecting citrus fruits from the field to postharvest-a review," Food Bioprocess Technol., vol. 9, no. 10, pp. 1623-1639, 2016.

[12] A. Folch-Fortuny, J. M. Prats-Montalbán, S. Cubero, J. Blasco, and A. Ferrer, "VIS/NIR hyperspectral imaging and N-way PLS-DA models for detection of decay lesions in citrus fruits," Chemom. Intell. Lab. Syst., vol. 156, pp. 241-248, 2016.

[13] X. Zhu and G. Li, "Rapid detection and visualization of slight bruise on apples using hyperspectral imaging,” Int. J. Food Prop., vol. 22, no. 1, pp. 1709-1719, 2019.

[14] Z. Du, X. Zeng, X. Li, X. Ding, J. Cao, and W. Jiang, "Recent advances in imaging techniques for bruise detection in fruits and vegetables,” Trends Food Sci. Technol., 2020.

[15] X. Zeng, Y. Miao, S. Ubaid, X. Gao, and S. Zhuang, "Detection and classification of bruises of pears based on thermal images,” Postharvest Biol. Technol., vol. 161, p. 111090, 2020.

[16] M. Zhang, Y. Jiang, C. Li, and F. Yang, "Fully convolutional networks for blueberry bruising and calyx segmentation using hyperspectral transmittance imaging," Biosyst. Eng., vol. 192, pp. 159-175, 2020. 
[17] Y. LeCun et al., "Backpropagation applied to handwritten zip code recognition," Neural Comput., vol. 1, no. 4, pp. 541-551, 1989.

[18] R. P. Lippmann, "Review of neural networks for speech recognition,” Neural Comput., vol. 1, no. 1, pp. 1-38, 1989.

[19] B. Yuan, "Efficient hardware architecture of softmax layer in deep neural network," in 2016 29th IEEE International System-on-Chip Conference (SOCC), 2016, pp. 323-326.

[20] A. Kamilaris and F. X. Prenafeta-Boldú, "Deep learning in agriculture: A survey,” Comput. Electron. Agric., vol. 147, pp. 70-90, 2018.

[21] J. Wan et al., "Deep learning for content-based image retrieval: A comprehensive study," in Proceedings of the 22nd ACM international conference on Multimedia, 2014, pp. 157-166.

[22] M. I. Razzak, S. Naz, and A. Zaib, "Deep learning for medical image processing: Overview, challenges and the future,” in Classification in BioApps, Springer, 2018, pp. 323-350.

[23] C. Tian, Y. Xu, L. Fei, and K. Yan, “Deep Learning for Image Denoising: A Survey,” Int. Conf. Genet. Evol. Comput., pp. 563-572, 2018.

[24] V. Leemans and M.-F. Destain, "A real-time grading method of apples based on features extracted from defects,” J. Food Eng., vol. 61, no. 1, pp. 83-89, 2004.

[25] J. Xing and J. De Baerdemaeker, "Bruise detection on 'Jonagold'apples using hyperspectral imaging,” Postharvest Biol. Technol., vol. 37, no. 2, pp. 152-162, 2005.

[26] D. Unay and B. Gosselin, "Automatic defect segmentation of 'Jonagold'apples on multi-spectral images: A comparative study,” Postharvest Biol. Technol., vol. 42, no. 3, pp. 271-279, 2006.

[27] D. Unay, B. Gosselin, O. Kleynen, V. Leemans, M.-F. Destain, and O. Debeir, "Automatic grading of Bi-colored apples by multispectral machine vision,” Comput. Electron. Agric., vol. 75, no. 1, pp. 204-212, 2011.

[28] S. H. Mohana and C. J. Prabhakar, "Stem-calyx recognition of an apple using shape descriptors," arXiv Prepr. arXiv1501.01083, 2015.

[29] S. R. Dubey and A. S. Jalal, "Apple disease classification using color, texture and shape features from images,” Signal, Image Video Process., vol. 10, no. 5, pp. 819-826, 2016.

[30] Y. Lu and R. Lu, "Histogram-based automatic thresholding for bruise detection of apples by structured-illumination reflectance imaging,” Biosyst. Eng., vol. 160, pp. 30-41, 2017.

[31] S. Zhang, X. Wu, S. Zhang, Q. Cheng, and Z. Tan, "An effective method to inspect and classify the bruising degree of apples based on the optical properties," Postharvest Biol. Technol., vol. 127, pp. 44-52, 2017.

[32] “Gömülü kamera sistemleri”, [Online]. https://www.matrix-vision.com/smart-cam-compactapplication-camera.html [Erişim tarihi: 21.05.2020.] 